\title{
HPA axis changes during the initial phase of psychosocial stressor exposure in male mice
}

\author{
Nicole Uschold-Schmidt ${ }^{1}$, Daniel Peterlik ${ }^{1}$, Andrea M Füchsl ${ }^{1}$ and Stefan O Reber ${ }^{1,2}$ \\ ${ }^{1}$ Department of Behavioural and Molecular Neurobiology, University of Regensburg, 93053 Regensburg, Germany \\ ${ }^{2}$ Clinic for Psychosomatic Medicine and Psychotherapy, Laboratory for Molecular Psychosomatics, University of Ulm, \\ Albert-Einstein-Allee 23, 89081 Ulm, Germany
}

Correspondence should be addressed to $S$ O Reber Email stefan.reber@ uniklinik-ulm.de

\begin{abstract}
Chronic subordinate colony (CSC) housing for 19 days results in unaffected basal morning corticosterone (CORT) levels despite a pronounced increase in adrenal mass, likely mediated by an attenuation of adrenal corticotropin (ACTH) responsiveness. Given that the pronounced increase in basal morning plasma CORT levels returns to baseline as early as $48 \mathrm{~h}$ after the start of CSC, it is likely that the attenuated ACTH responsiveness develops already during this initial phase. This was tested in the present study. In line with previous findings, basal morning plasma CORT levels were elevated following $10 \mathrm{~h}$, but not $48 \mathrm{~h}$, of CSC exposure. Basal morning plasma ACTH concentrations and relative in vivo adrenal CORT content were increased following $10 \mathrm{~h}$ and to a lesser extent following $48 \mathrm{~h}$ of CSC exposure, positively correlating. Relative in vitro adrenal CORT secretion in response to ACTH (100 nM) and kidney protein expression of 11ß-hydroxysteroid dehydrogenase type 2 (HSD11B2) were unaffected following both time points. Adrenal mRNA expression of key steroidogenic enzymes was unaffected/decreased following $10 \mathrm{~h}$ and unaffected/increased following $48 \mathrm{~h}$ of CSC exposure. Together, our findings suggest that basal plasma hypercorticism during the initial CSC phase is mainly prevented by an attenuation of pituitary ACTH release. An increased absolute adrenal weight following $10 \mathrm{~h}$, but not $48 \mathrm{~h}$, of CSC exposure indicates that restoration of normal adrenal mass also adds to a lesser extent to prevent basal hypercorticism. A contributing role of alterations in enzymatic CORT degradation and steroidogenic enzyme availability is likely, but has to be further addressed in future studies.
\end{abstract}

\author{
Key Words \\ - psychosocial stress \\ - chronic subordinate colony \\ (CSC) housing \\ - HPA axis \\ - adrenal glands \\ - ACTH \\ - hypercorticism \\ - corticosterone
}

\section{Introduction}

Exposure to acute stressful stimuli leads to the activation of both the sympathetic nervous system and the hypothalamo-pituitary-adrenal (HPA) axis and, consequently, to the systemic release of catecholamines and glucocorticoids (GCs). These stress hormones, in turn, trigger physiological alterations enabling an organism to adjust to the new situation and to exhibit an adequate behavioral response (for a review, see Chrousos (1998) and
Charmandari et al. (2005)). This indicates that the acute stress response is generally beneficial and increases an individual's chance of survival. However, if the stress systems are activated over a prolonged period of time, chronically elevated levels of plasma GCs can promote the development of somatic and affective disorders (for a review, see Sapolsky (1996), McEwen (2000) and Vanitallie (2002)). Thus, it is adaptive for an individual to habituate

Published by Bioscientifica Ltd 
as fast as possible to prolonged and not life-threatening homotypic stressors (Kudielka et al. 2006, Sasse et al. 2008).

Although it is generally accepted that habituation to a prolonged homotypic stressor does not occur if the stressor is of social nature (for review, see Bartolomucci (2007)), we have just recently provided the first evidence that this does not hold true for the chronic subordinate colony (CSC) housing paradigm, an adequate and clinically relevant mouse model of chronic psychosocial stress (Reber et al. 2007, Reber \& Neumann 2008, Slattery et al. 2012, Uschold-Schmidt et al. 2012). CSC mice exhibit unaffected basal morning plasma corticosterone (CORT) levels, despite significantly enlarged adrenal glands following 19 days of CSC compared with single-housed control (SHC) mice. A general breakdown of HPA axis functionality in chronically stressed mice, explaining this controversy, can be excluded here, as CSC mice compared with the SHC mice exhibit an even more pronounced CORT response to an acute heterotypic stressor. The latter finding, indicating functionally not compromised adrenal glands in CSC mice, is further supported by data showing increased availability and mobilization capacity of the CORT precursor molecule cholesterol in CSC mice compared with the SHC mice, contributing to their increased in vivo CORT response during acute heterotypic stressor exposure (Füchsl et al. 2013). Moreover, relative adrenal mRNA expression of the key steroidogenic enzymes: steroidogenic acute regulatory protein (Star), side-chain cleavage enzyme (Cyp11a1), and 11ß-hydroxylase (Cyp11b1) (for a review, see Miller (1988) and Biason-Lauber (1998)) is not affected or even increased following 19 days of CSC (Uschold-Schmidt et al. 2012).

In concert with the lower relative adrenal in vitro ACTH responsiveness following 19 days of CSC, these data strongly suggest that CSC mice prevent the health-compromising consequences of enlarged and fully functional adrenal glands, namely increased basal CORT levels, by reducing relative adrenal sensitivity to the main CORT secretagogue ACTH.

Although elevated basal morning plasma CORT levels (observed following 10 and $24 \mathrm{~h}$ ) in CSC mice return to baseline as early as $48 \mathrm{~h}$ after the start of stressor exposure (Reber et al. 2007, 2011), the reduction in adrenal ACTH responsiveness has been investigated and described only after 19 days of CSC so far. It is, thus, the aim of the present study to reveal that CSC-induced attenuation of relative in vitro adrenal ACTH responsiveness develops already during the initial $48 \mathrm{~h}$ of CSC, the time period in which elevated morning basal plasma CORT levels return to baseline.

To test this in the present study, we investigated the effects of $10 \mathrm{~h}$, as basal morning plasma CORT levels have been found to be strongly increased at this time point (Reber et al. 2011), and $48 \mathrm{~h}$ of CSC on i) basal morning plasma CORT and ACTH concentrations, ii) relative in vivo adrenal CORT content, iii) relative in vitro adrenal ACTH responsiveness, iv) absolute and relative adrenal weights, and v) relative adrenal mRNA expression of the key steroidogenic enzymes Star, Cyp11a1, and Cyp11b1. Given that the attenuated ACTH responsiveness after 19 days of CSC exposure developed in both the left and right adrenal glands (Uschold-Schmidt et al. 2012), relative in vivo adrenal CORT content, relative in vitro adrenal ACTH responsiveness, and relative adrenal mRNA expression levels of Star, Cyp11a1, and Cyp11b1 were assessed only in the left adrenal gland of an experimental mouse. Nevertheless, absolute and relative adrenal weight as assessed in both the left and right adrenal glands. Furthermore, vi) relative protein

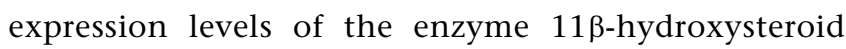
dehydrogenase type 2 (HSD11B2), mediating the inactivation of CORT (for review, see Seckl \& Walker (2001)), were assessed following 10 and $48 \mathrm{~h}$ of CSC exposure in the kidneys of both the SHC and CSC mice.

\section{Materials and methods}

\section{Animals}

Male C57BL/6 mice (Charles River, Sulzfeld, Germany) weighing 19-22 g (experimental mice) were individually housed in standard polycarbonate mouse cages $(16 \times 22 \times 14 \mathrm{~cm})$ for 1 week before starting the CSC paradigm. As described previously (Füchsl et al. 2013), the male offspring (weighing 30-35 g) of high-anxiety-related behavior female mice (kindly provided by Prof. Dr R Landgraf, Max Planck Institute of Psychiatry, Munich) and C57BL/6 male mice (Charles River) were used as dominant animals. All mice were kept under standard laboratory conditions ( $12 \mathrm{~h}$ light: $12 \mathrm{~h}$ darkness cycle, lights on at $0600 \mathrm{~h}, 22^{\circ} \mathrm{C}$ and $60 \%$ humidity) and had free access to tap water and standard mouse diet. All experimental protocols were approved by the Committee on Animal Health and Care of the local government and conformed to international guidelines on the ethical use of animals. All efforts were made to minimize the number of animals used and their suffering.

\section{Experimental procedures}

Experimental mice were either stressed by exposure to the CSC paradigm or SHC in a weight-matched setup.

Experimental mice were killed in the morning between 0800 and $1000 \mathrm{~h}$ following either $10 \mathrm{~h}$ (start of CSC

Published by Bioscientifica Ltd 
between 2200 and 2400 h) or 48 h (start of CSC between 0800 and $1000 \mathrm{~h}$ ) of CSC exposure and body weight was assessed. To reveal the effects of CSC on absolute and relative adrenal weights, in vivo adrenal CORT content (only the left adrenal gland), in vitro adrenal ACTH responsiveness (only the left adrenal gland), and relative adrenal mRNA expression levels of Star, Cyp11a1, and Cyp11b1 (only the left adrenal gland), the left and right adrenal glands were removed, pruned of fat, and treated according to the respective readout parameter as described below. To assess the effects of CSC on relative protein expression levels of HSD11B2, the left kidney was removed and treated as described below. Furthermore, trunk blood was collected from the SHC and CSC mice for the determination of basal morning plasma CORT and ACTH concentrations following 10 and $48 \mathrm{~h}$ of CSC exposure.

\section{CSC paradigm}

The CSC paradigm was conducted as described previously (Reber et al. 2007, Reber \& Neumann 2008, Singewald et al. 2009, Slattery et al. 2012, Uschold-Schmidt et al. 2012). Briefly, 1 week after arrival, experimental mice were weighed and in a weight-matched manner assigned to either the SHC or the CSC group. The SHC mice remained undisturbed in their home cages except for change of bedding once a week. The CSC mice were housed in groups of four together with a dominant male for either 10 or $48 \mathrm{~h}$, in order to induce psychosocial stress. The SHC and CSC mice were again weighed in the morning between 0800 and $1000 \mathrm{~h}$ following 10 or $48 \mathrm{~h}$ of CSC exposure, immediately before being killed by decapitation.

\section{Trunk blood sampling}

In the morning between 0800 and $1000 \mathrm{~h}$ following either 10 or $48 \mathrm{~h}$ of CSC exposure, the SHC and CSC mice were rapidly killed by decapitation under $\mathrm{CO}_{2}$ anesthesia within 3 min after entering the animal room. Trunk blood was collected in EDTA-coated tubes (Sarstedt, Nümbrecht, Germany) on ice and centrifuged at $4{ }^{\circ} \mathrm{C}$ (4200 g, $10 \mathrm{~min})$. Plasma samples were stored at $-20^{\circ} \mathrm{C}$ until assayed for plasma CORT and ACTH concentrations using commercially available ELISA kits for CORT and ACTH (IBL International, Hamburg, Germany).

\section{Determination of adrenal weight}

After decapitation, the left and right adrenal glands of each mouse were removed, pruned of fat, and weighed separately. The left adrenal glands were then used for the determination of in vivo adrenal CORT content, in vitro ACTH stimulation, or assessment of mRNA expression levels of Star, Cyp11a1, and Cyp11b1. Values represent absolute adrenal weight $(\mathrm{mg})$ or relative adrenal weight (mg/body weight in $\mathrm{g}$ ). In addition, the sum of left and right absolute and relative adrenal weights was calculated for each mouse. Owing to methodological problems, three 48-h SHC mice and one 48-h CSC mouse had to be excluded from the analysis of absolute and relative adrenal weights. These mice were, therefore, also excluded from the analysis of body weight.

\section{Determination of in vivo adrenal CORT content}

After removal, pruning of fat, and weighing, the left adrenal gland of each mouse was immediately frozen in liquid nitrogen. Further processing was performed as described previously (Uschold-Schmidt et al. 2012). Briefly, the left adrenal glands were homogenized with $20 \%$ ethanol in $1 \times$ PBS on ice and centrifuged at $4{ }^{\circ} \mathrm{C}$ $(2688 \mathrm{~g}, 5 \mathrm{~min})$, and supernatants were collected and stored at $-20^{\circ} \mathrm{C}$ until assayed for CORT concentrations using a commercially available ELISA (IBL International, Hamburg, Germany).

\section{ACTH stimulation of adrenal explants in vitro}

ACTH stimulation was performed as described previously (Uschold-Schmidt et al. 2012). Briefly, after removal, pruning of fat, and weighing, the left adrenal gland of each mouse was stored in ice-cold DMEM/F-12 (Life Technologies, Inc.) containing $0.1 \%$ BSA until all mice were killed and adrenals removed. Afterwards, each left adrenal gland was cut into two halves each containing cortical and medullary tissue. The halves were then weighed and pre-incubated in $200 \mu \mathrm{l}$ DMEM/F-12 for $4 \mathrm{~h}\left(37^{\circ} \mathrm{C}, 95 \%\right.$ $\mathrm{O}_{2}$ and $5 \% \mathrm{CO}_{2}$ ) before any further treatment. Culture medium was then replaced, and each half of one adrenal gland was incubated with either a medium containing saline (basal) or a medium containing ACTH (100 nM) for $6 \mathrm{~h}$ at $37^{\circ} \mathrm{C}\left(95 \% \mathrm{O}_{2}\right.$ and $\left.5 \% \mathrm{CO}_{2}\right)$. Afterwards, the supernatant of each adrenal explant was carefully removed and stored at $-20^{\circ} \mathrm{C}$ until assayed for CORT concentrations using a commercially available ELISA (IBL International).

\section{ELISA for CORT and ACTH}

Plasma and supernatant samples were analyzed using commercially available ELISA kits for CORT (analytical

Published by Bioscientifica Ltd. 
sensitivity $<1.631 \mathrm{nmol} / \mathrm{l}$ and intra-assay and inter-assay coefficients of variation $(\mathrm{CV}) \leq 6.35 \%$; IBL International) and ACTH (plasma samples only; analytical sensitivity $0.22 \mathrm{pg} / \mathrm{ml}$ and intra-assay and inter-assay CV $\leq 7.1 \%$; IBL International). Supernatant CORT concentrations ( $\mathrm{ng} / \mathrm{ml})$ were calculated in relation to the respective left adrenal explant weights $(\mathrm{ng} / \mathrm{ml}$ per $\mathrm{mg}$; in vitro adrenal ACTH stimulation; equal to relative in vitro CORT secretion) or in relation to the respective left adrenal gland weights (ng/ml per mg; in vivo adrenal CORT content; equal to relative adrenal in vivo adrenal CORT content). Owing to methodological problems, one 10-h SHC mouse, five 10-h CSC mice, and two 48-h CSC mice had to be excluded from the analysis of plasma CORT concentrations. Furthermore, for the same reason, one 10-h SHC mouse and two 10-h CSC mice had to be excluded from the analysis of relative in vivo adrenal CORT content and three 10-h SHC mice from the analysis of relative in vitro adrenal CORT secretion.

\section{Western blotting for the assessment of HSD11B2 protein levels in the kidney}

Protein expression analysis was performed as described recently (Füchsl et al. 2013). The left kidney of each mouse was removed and immediately shock-frozen in liquid nitrogen and stored at $-80^{\circ} \mathrm{C}$ until assayed. For protein extraction, the frozen kidneys were homogenized separately in EDTA lysis buffer (50 mM EDTA, $250 \mathrm{mM} \mathrm{NaCl}, 0.5 \mathrm{mM}$ HEPES, $0.5 \%$ Igepal, and 10\% Complete Mini Protease Inhibitor; Roche Diagnostics $\mathrm{GmbH}$ ), and total protein concentration was determined using a commercially available detection kit (Bicinchoninic Acid Protein Assay Kit, Thermo Scientific, Rockford, IL, USA). Western blotting was carried out using $40 \mu \mathrm{g}$ of protein/kidney. Samples were loaded on SDS-polyacrylamide gels (10\%) and subsequently transferred onto nitrocellulose membranes. The membranes were then blocked for $1 \mathrm{~h}$ at RT in 5\% milk powder diluted in Tris-buffered saline (TBS) with $0.05 \%$ Tween-20 (TBST; Sigma-Aldrich) before being probed with primary rabbit anti-HSD11B2 antibody (1:400; Santa Cruz Biotechnology, Inc., Heidelberg, Germany) overnight at $4{ }^{\circ} \mathrm{C}$. Visualization was performed using HRP-conjugated goat anti-rabbit antibody (1:2000; Cell Signaling Technology, New England Biolabs $\mathrm{GmbH}$, Frankfurt am Main, Germany) and later using ECL Western Blotting Detection Reagents (GE Healthcare, Freiburg, Germany). Immunoblots were digitized using Molecular Imager ChemiDoc XRS + system and analyzed using Image the Lab Software (Bio-Rad Laboratories $\mathrm{GmbH}$ ). Afterwards, the membranes were stripped using the Re-Blot Plus Mild Antibody Stripping
Solution (Millipore GmbH, Schwalbach, Germany), blocked twice with $5 \%$ milk powder in TBST for $5 \mathrm{~min}$, and probed with primary rabbit anti- $\beta$-tubulin antibody (1:1000, Cell Signaling Technology, New England Biolabs GmbH, Frankfurt am Main, Germany) for $1 \mathrm{~h}$ at RT. Visualization and digitization were performed as described above (HRPconjugated goat anti-rabbit antibody, 1:2000). Bands were detected at $\sim 40 \mathrm{kDa}$ for HSD11B2 and $\sim 50 \mathrm{kDa}$ for the loading control $\beta$-tubulin, as specified by the manufacturers. The expression of HSD11B2 was normalized to the respective $\beta$-tubulin protein expression and averaged per group.

\section{Quantitative real-time PCR for Star, Cyp11a1, and Cyp11b1 using TaqMan technology}

The quantitative real-time PCR (qPCR) was performed as described recently (Reber et al. 2011, Uschold-Schmidt et al. 2012). Briefly, total RNA was prepared from the left adrenal tissue using the RNeasy Mini Kit (Qiagen) and reverse-transcribed into first-strand cDNA (25 ng/ $\mu$ l RNA for each mouse, AffinityScript Multiple Temperature cDNA Synthesis Kit, Agilent Technologies, Waldbronn, Germany). The expression levels of murine Star, Cyp11a1, and Cyp11b1 were quantified by TaqMan qPCR (7500 Fast Real-Time PCR System; Applied Biosystems) in single-tube reactions $(20 \mu \mathrm{l})$ in 96-well plates. Primers and probes used were as follows: Star forward, GGA GCT CTC TGC TTG GTT CTC A; Star reverse, CAC CTC TCC CTG CTG GAT GTA G; Star probe, TCT ATA GTG ACC AGG AGC TGT; Cyp11a1 forward, CCG GAG CGG TTC CTT GTG CC; Cyp11a1 reverse, CAG GAC CCC AAT GGG CCT CTG A; Cyp11a1 probe, CTG GGT GGC CTA TCA CCA GTA; and Cyp11b1 forward, GCA GAG ATG ATG CTC CTG C; Cyp11b1 reverse, CCG CAC ATC CTC TTT CTC TTG; Cyp11b1 probe, TGT GCT GAA ATC CTT CCA CGT. The probes were labeled $5^{\prime}$ with 6-carboxyfluorescein (FAM) and $3^{\prime}$ with 6-carboxytetramethylrhodamine (TAMRA). TaqMan qPCR was performed using $2 \mu \mathrm{l}$ cDNA, $0.15 \mu \mathrm{l}$ forward and reverse primers (each $18 \mu \mathrm{M}), 1.4 \mu \mathrm{l}$ probe $(5 \mu \mathrm{M})$, $10 \mu \mathrm{l}$ Mastermix $+0.3 \mu \mathrm{l}$ ROX reference dye (Brilliant III Ultra-Fast QPCR Master Mix, Agilent Technologies, Waldbronn, Germany), and $0.6 \mu$ l glyceraldehyde-3-phosphate dehydrogenase (Gapdh) Mix (served as a reference; Applied Biosystems) and made up to the final volume of $20 \mu \mathrm{l}$ with sterile $\mathrm{H}_{2} \mathrm{O}$. Cycling was as follows: $95^{\circ} \mathrm{C}$ for 3 min followed by 40 repeats of $95^{\circ} \mathrm{C}$ for $15 \mathrm{~s}$ and $60^{\circ} \mathrm{C}$ for $30 \mathrm{~s}$. Expression value normalized to Gapdh mRNA expression was quantified for each mouse and averaged per group. SHC values were set to $100 \%$, and the percentage change in mRNA expression following 10 or $48 \mathrm{~h}$ of CSC was calculated.

Published by Bioscientifica Ltd. 


\section{Statistical analysis}

For statistical comparisons, the software package SPSS statistics (version 19.0) was used. Data of the two experimental groups (SHC vs CSC) were compared employing the Student's $t$-test. The absolute and relative left and right adrenal weights (factors CSC and body side), plasma CORT and ACTH concentrations, left in vivo adrenal CORT content, HSD11B2 protein expression in the kidney, left adrenal mRNA expression of Star, Cyp11a1, and Cyp11b1 (factors CSC and duration), and left in vitro adrenal CORT secretion (factors CSC and ACTH) were compared using a two-way ANOVA followed by a post hoc Bonferroni's test when appropriate. In addition, for statistically significant differences, the effect size (Cohen's $d$ values; standardized mean difference) as a measure of the magnitude of the difference between the groups was calculated. Cohen's $d=0.2-0.5$ is conceived as a small effect, $d=0.5-0.8$ as a medium effect, and $d \geq 0.8$ as a large effect. Correlation analysis of plasma ACTH concentrations with left in vivo adrenal CORT content in the CSC mice was carried out employing Pearson's correlation. Data represent means + s.E.M. Significance was taken at $P<0.05$.

\section{Results}

Plasma CORT concentrations are increased following $10 \mathrm{~h}$, but not $48 \mathrm{~h}$, of CSC exposure

Basal morning plasma CORT concentrations following 10 and $48 \mathrm{~h}$ of CSC exposure were found to be dependent on the factors $\operatorname{CSC}\left(F_{1,120}=32.24 ; P<0.001\right)$ and duration $\left(F_{1,120}=38.46 ; P<0.001\right)$ and also on the interaction between both the factors $\left(F_{1,120}=26.97 ; P<0.001\right)$ (Fig. 1A). Post hoc analysis revealed significantly increased plasma CORT concentrations in the CSC mice compared with the SHC mice following $10 \mathrm{~h}(P<0.001 ; d=1.42)$, but not $48 \mathrm{~h}$, of CSC exposure. Consequently, basal morning plasma CORT concentrations were significantly lower in the CSC mice at the 48-h time point compared with the 10-h time point $(P<0.001 ; d=1.56)$ (Fig. $1 \mathrm{~A})$.

\section{Plasma ACTH levels are increased following both 10 and $48 \mathrm{~h}$ of CSC exposure}

Basal morning plasma ACTH concentrations following 10 and $48 \mathrm{~h}$ of CSC exposure were found to be dependent on the factor $\operatorname{CSC}\left(F_{1,127}=23.63 ; P<0.001\right)$ as well as the factor duration $\left(F_{1,127}=11.63 ; P=0.001\right)$ (Fig. 1B). Although post hoc analysis revealed a significant increase
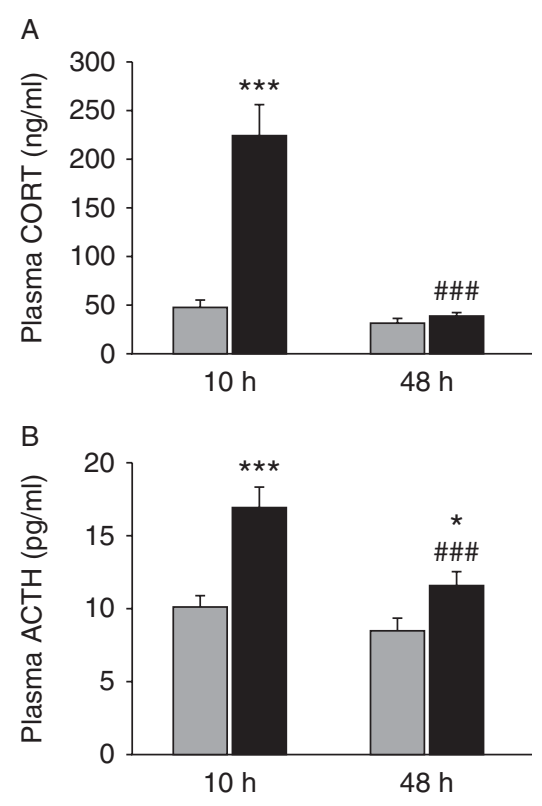

Figure 1

Effects of 10 and $48 \mathrm{~h}$ of CSC exposure on basal morning plasma CORT and ACTH concentrations. SHC and CSC mice were decapitated in the morning between 0800 and $1000 \mathrm{~h}$ following either $10 \mathrm{~h}$ ( $A$ and B; left panel) or $48 \mathrm{~h}$ ( $A$ and $B$; right panel) of CSC exposure and trunk blood was collected. Afterwards, plasma CORT ( $\mathrm{ng} / \mathrm{ml}$; SHC, $n=29-30 ; \operatorname{CSC}, n=31-34 ; \mathrm{A})$ and plasma ACTH (pg/ml; SHC, $n=30$; CSC, $n=35-36 ;$ B) concentrations were determined. Gray bar, SHC; black bar, CSC. Data represent means + s.E.M.

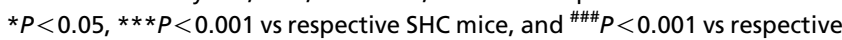
10-h time point.

in plasma ACTH levels in the CSC mice compared with SHC mice following both $10 \mathrm{~h}(P<0.001 ; d=1.04)$ and $48 \mathrm{~h}(P=0.032 ; d=0.62)$ of CSC exposure, the increase was less pronounced at the latter time point (10 vs $48 \mathrm{~h} \mathrm{CSC}$, $P<0.001 ; d=0.78$; Fig. 1B).

\section{Relative in vivo adrenal CORT content is increased following both 10 and $48 \mathrm{~h}$ of CSC exposure}

Relative (per mg tissue) in vivo adrenal CORT content following 10 and $48 \mathrm{~h}$ of CSC exposure was found to be dependent on the factors CSC $\left(F_{1,57}=74.49 ; P<0.001\right)$ and duration $\left(F_{1,57}=9.57 ; P=0.003\right)$ as well as on the interaction between both the factors $\left(F_{1,57}=10.57\right.$; $P=0.002$ ) (Fig. 2A). Although post hoc analysis revealed an increased relative in vivo adrenal CORT content in the CSC mice compared with the SHC mice following both $10 \mathrm{~h}(P<0.001 ; d=2.60)$ and $48 \mathrm{~h}(P<0.001$; $d=1.69$ ) of CSC exposure, it was less pronounced at the latter time point ( 10 vs $48 \mathrm{~h}$ CSC, $P<0.001 ; d=1.17$; Fig. 2A). Interestingly, statistical analysis further revealed

Published by Bioscientifica Ltd. 

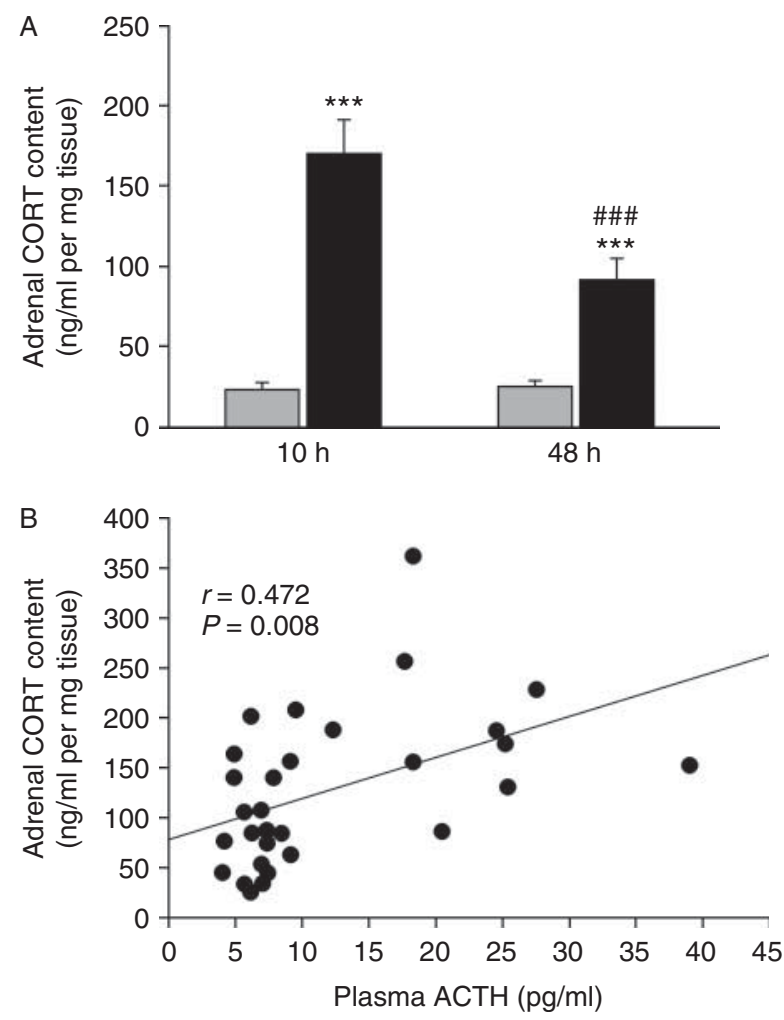

Figure 2

Effects of 10 and $48 \mathrm{~h}$ of CSC exposure on relative in vivo adrenal CORT content. SHC and CSC mice were killed following either $10 \mathrm{~h}$ (SHC, $n=15$; CSC, $n=14$ ) or $48 \mathrm{~h}$ (SHC and CSC, $n=16$ ) of CSC exposure. The left and right adrenal glands were removed, pruned of fat, and weighed. Afterwards, the left adrenal glands were homogenized and relative adrenal CORT content ( $\mathrm{ng} / \mathrm{ml}$ per mg tissue) was determined in the supernatants (A). Gray bar, SHC; black bar, CSC. Data represent means + s.E.M. $* * * P<0.001$ vs respective SHC mice and ${ }^{\# \#} P<0.001$ vs respective 10 -h time point. Additionally, Pearson's correlation analysis was performed for basal morning plasma ACTH concentrations $(\mathrm{pg} / \mathrm{ml})$ with relative in vivo adrenal CORT content ( $\mathrm{ng} / \mathrm{ml}$ per mg tissue) in the CSC mice (10 and $48 \mathrm{~h} ; n=30 ; \mathrm{B})$.

a positive correlation for basal morning plasma ACTH concentrations with relative in vivo adrenal CORT content in the CSC mice (10 and $48 \mathrm{~h}$; Pearson's $r=0.472$; $P=0.008$; Fig. 2B).

\section{Relative in vitro adrenal CORT secretion in response to ACTH is not affected following both 10 and $48 \mathrm{~h}$ of CSC exposure}

Relative (per mg tissue) in vitro adrenal CORT secretion was found to be dependent only on the factor ACTH treatment following both $10 \mathrm{~h}\left(F_{1,58}=19.51 ; P<0.001\right)$ and $48 \mathrm{~h}$ of CSC exposure $\left(F_{1,64}=19.74 ; P<0.001\right)$. Post hoc analysis revealed that relative in vitro adrenal CORT secretion in both the SHC and CSC mice was significantly increased following ACTH treatment compared with the respective basal values at both time points (for each $P \leq 0.004$; $d \geq 0.98$; Fig. $3 \mathrm{~A}$ and $\mathrm{B})$.

\section{Body weight is decreased following 10 and $48 \mathrm{~h}$ of CSC exposure}

Following both $10 \mathrm{~h}(P=0.006 ; d=0.70$; Fig. $4 \mathrm{~B})$ and $48 \mathrm{~h}$ $(P<0.001 ; d=1.02 ;$ Fig. 4D) of CSC exposure, body weight was significantly decreased in the CSC mice compared with the SHC mice. Importantly, the body weights of the SHC and CSC mice were neither different before the 10-h CSC exposure nor before the 48-h CSC exposure (Fig. 4A and C).

\section{Relative left and right adrenal weight is increased following 10 and $48 \mathrm{~h}$ of CSC exposure}

Following 10 and $48 \mathrm{~h}$ of CSC exposure, relative adrenal weight of both adrenal glands (the left and right adrenal weights of each mouse was summed up) was significantly increased in the CSC mice compared with the SHC mice $(10 \mathrm{~h}, P \leq 0.001 ; d=1.38 ; 48 \mathrm{~h}, P \leq 0.001 ; d=0.92$; Fig. $5 \mathrm{~B}$ and $\mathrm{D})$.

Statistical analysis, considering the factors body side and CSC exposure, revealed a significant main effect of both the factors following $10 \mathrm{~h}$ (body side, $F_{1,128}=41.92$; $P<0.001 ;$ CSC, $F_{1,128}=55.56 ; P<0.001$ ) and $48 \mathrm{~h}$ (body
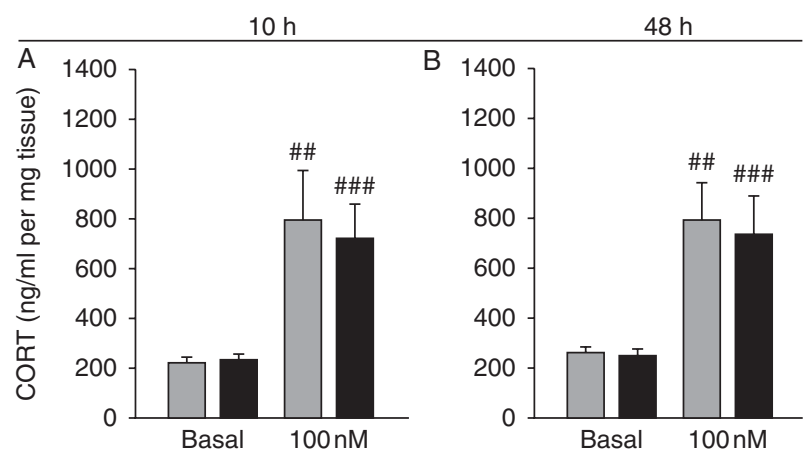

Figure 3

Effects of 10 and $48 \mathrm{~h}$ of CSC exposure on in vitro adrenal CORT secretion in response to ACTH. SHC and CSC mice were killed following either $10 \mathrm{~h}$ (A) or $48 \mathrm{~h}$ (B) of CSC exposure. The left and right adrenal glands were removed, pruned of fat, and weighed separately. Afterwards, the left adrenal glands were cut into two halves. These left adrenal halves of the SHC (10 h, $n=11 ; 48 \mathrm{~h}, n=14)$ and CSC (10 h, $n=20 ; 48 \mathrm{~h}, n=20)$ groups were weighed again and incubated with a medium containing either saline (basal) or $100 \mathrm{nM} \mathrm{ACTH}$ for $6 \mathrm{~h}$. Afterwards, CORT concentrations $(\mathrm{ng} / \mathrm{ml}$ per $\mathrm{mg}$ tissue) were determined in the supernatants. Gray bar, SHC; black bar, CSC. Data represent means + S.E.M. ${ }^{\# \#} P<0.01$ and ${ }^{\# \#} P<0.001$ vs respective basal values. 


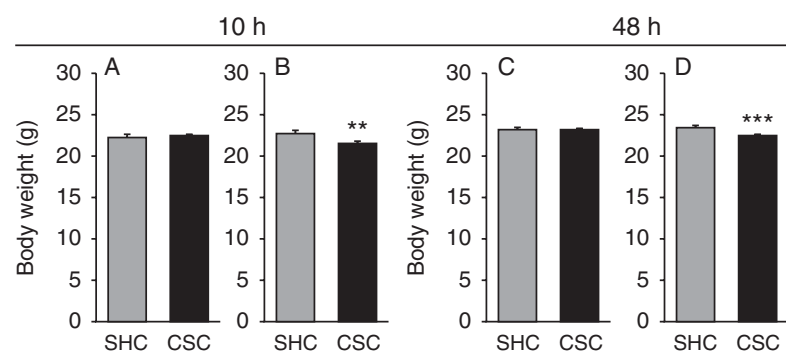

Figure 4

Effects of 10 and $48 \mathrm{~h}$ of CSC exposure on body weight. Body weight (g) was assessed in the SHC (10 h, $n=30 ; 48 \mathrm{~h}, n=27)$ and CSC (10 h, $n=36 ; 48 \mathrm{~h}$, $n=35$ ) mice before the start of CSC exposure (A and C) and following $10 \mathrm{~h}$ (B) and $48 \mathrm{~h}(\mathrm{D})$ of CSC exposure before the mice were killed by decapitation. Gray bar, SHC; black bar, CSC. Data represent means + S.E.M. $* * P<0.01$ and $* * * P<0.001$ vs respective $\mathrm{SHC}$ mice.

side, $\quad F_{1,120}=93.20 ; \quad P<0.001 ; \quad$ CSC,$\quad F_{1,120}=19.71$; $P<0.001$ ) of CSC exposure (Fig. 5A and C). Post hoc testing further revealed that relative weight of both the left $(10 \mathrm{~h}$, $P<0.001 ; d=1.31 ; 48 \mathrm{~h}, P<0.001 ; d=1.01)$ and right (10 h, $P<0.001 ; d=1.30 ; 48$ h, $P=0.020 ; d=0.59$ ) adrenal glands was increased in the CSC mice compared with the SHC mice following 10 and $48 \mathrm{~h}$ of CSC exposure. Moreover, relative weight of the left adrenal gland was increased compared with that of the right adrenal gland in both the SHC and CSC mice (for each $P<0.001$ and $d \geq 1.07$; Fig. $5 \mathrm{~A}$ and $\mathrm{C}$ ) following $10 \mathrm{~h}$ as well as $48 \mathrm{~h}$ of CSC exposure.

\section{Absolute left and right adrenal weight is increased following $10 \mathrm{~h}$, but not $48 \mathrm{~h}$, of CSC exposure}

Following $10 \mathrm{~h}$ of CSC exposure, absolute weight of both the adrenal glands (the left and right adrenal weights of each mouse were summed up) was significantly increased in the CSC mice compared with the SHC mice $(P<0.001$; $d=1.33$; Fig. $5 \mathrm{~F}$ ), an effect that was absent after $48 \mathrm{~h}$ of CSC exposure (Fig. $5 \mathrm{H}$ ).

Statistical analysis, considering the factors body side and CSC exposure, revealed a significant main effect of both the factors following $10 \mathrm{~h}$ of CSC exposure (body side, $F_{1,128}=80.27 ; P<0.001$; CSC exposure, $F_{1,128}=46.57$; $P<0.001)$ and of only the factor body side $\left(F_{1,120}=116.75\right.$; $P<0.001)$ following $48 \mathrm{~h}$ of CSC exposure. Post hoc analysis further revealed that absolute weight of both the left $(P<0.001 ; d=1.23)$ and right $(P<0.001 ; d=1.15)$ adrenal glands was increased in the CSC mice compared with the SHC mice following $10 \mathrm{~h}$ of CSC exposure. Moreover, absolute weight of the left adrenal gland was increased compared with that of the right adrenal gland in both the
SHC and CSC mice following both 10 and $48 \mathrm{~h}$ of CSC exposure (for each $P<0.001 ; d \geq 1.46$; Fig. $5 \mathrm{E}$ and $\mathrm{G}$ ).

\section{Relative protein expression levels of $11 \beta-H S D 2$ in the kidney are not affected following 10 and $48 \mathrm{~h}$ of CSC exposure}

Relative (per $40 \mu \mathrm{g}$ of total protein) $11 \beta$-HSD2 protein expression in the kidney was affected neither by the factor CSC nor by the factor duration (Fig. 6A and B).

\section{Relative adrenal mRNA expression levels of Star, Cyp11a1, and Cyp11b1 are unaffected or decreased following $10 \mathrm{~h}$ and unaffected or even increased following $48 \mathrm{~h}$ of CSC exposure}

Relative adrenal mRNA expression of Star was affected neither by the factor CSC nor by the factor duration following both time points (Table 1). However, relative adrenal mRNA expression of Cyp11a1 following 10 and $48 \mathrm{~h}$ of CSC exposure was found to be dependent on
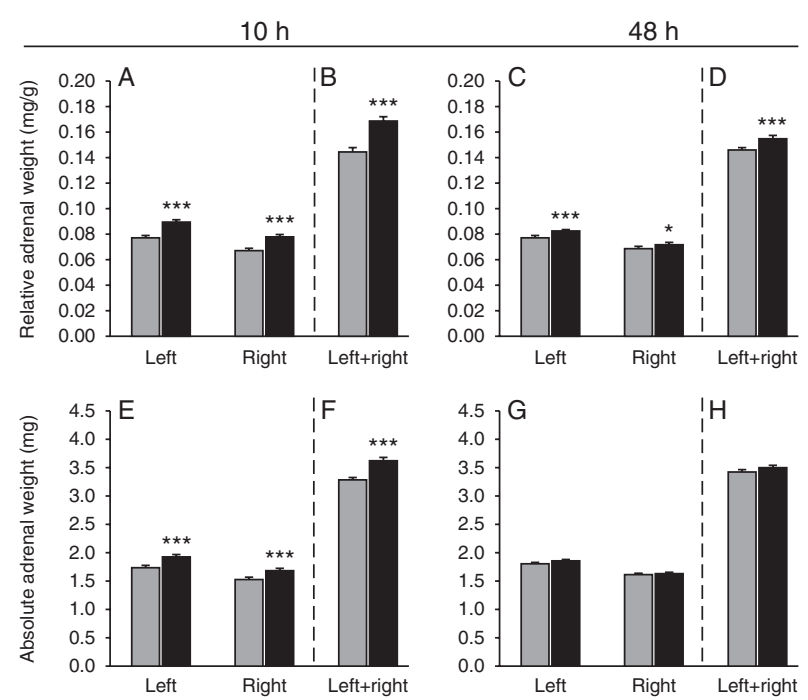

Figure 5

Effects of 10 and $48 \mathrm{~h}$ of CSC exposure on relative and absolute adrenal weights. SHC and CSC mice were killed following either $10 \mathrm{~h}(\mathrm{~A}, \mathrm{~B}, \mathrm{E}$ and $\mathrm{F}$ ) or $48 \mathrm{~h}$ ( $C, \mathrm{D}, \mathrm{G}$ and $\mathrm{H}$ ) of CSC exposure. The left and right adrenal glands were removed, pruned of fat, and weighed separately. The relative ( $\mathrm{mg} / \mathrm{g}$; $A, B, C$ and $D$ ) and absolute ( $m g ; E, F, G$ and $H$ ) weights of the left and right adrenal glands (A, C, E and G) of the SHC (10 h, $n=30 ; 48 \mathrm{~h}, n=27)$ and CSC (10 $\mathrm{h}, n=36 ; 48 \mathrm{~h}, n=35)$ mice are shown. In addition, the sum of relative $(B$ and $D)$ and absolute ( $F$ and $H$ ) left and right adrenal weights of the SHC and CSC mice is shown for both time points. Symbols indicating significant differences are only shown for effects between the groups. For significant within-group differences, see detailed information given in the Results section. Gray bar, SHC; black bar, CSC. Data represent means+ S.E.M. $\star P<0.05$ and $* * * P<0.001$ vs respective SHC mice. 


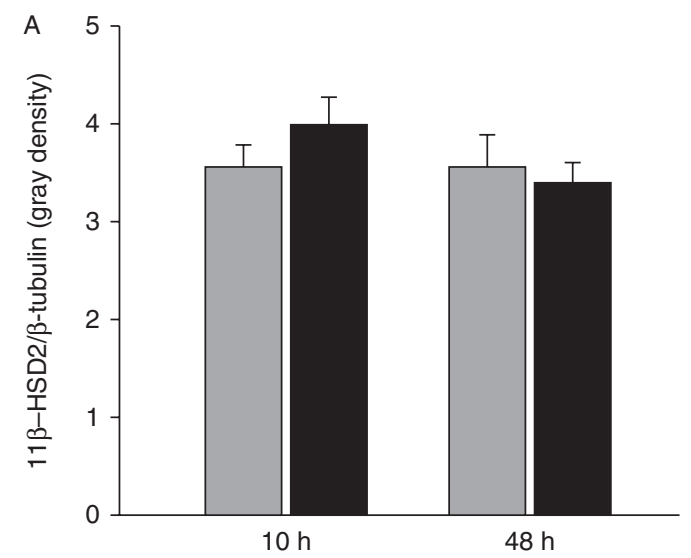

B

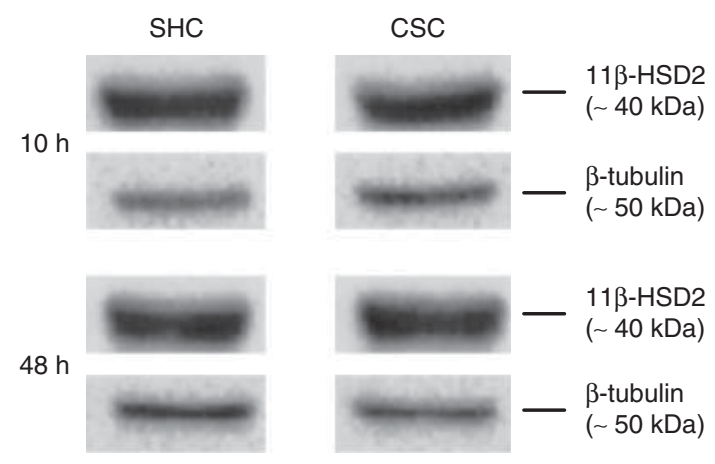

\section{Figure 6}

Effects of 10 and $48 \mathrm{~h}$ of CSC exposure on the relative protein expression levels of HSD11B2 in the kidney. SHC and CSC mice were killed following either $10 \mathrm{~h}$ (SHC and CSC, $n=8$; A, left panel) or $48 \mathrm{~h}$ (SHC, $n=8 ; \operatorname{CSC}: n=7$; $A$, right panel) of CSC exposure. The left kidney was removed and protein was extracted for the determination of HSD11B2 protein expression (gray density) normalized to the expression of the loading control $\beta$-tubulin. Gray bar, SHC; black bar, CSC. Data represent means + s.E.M. In addition, representative images of the bands detected for HSD11B2 ( $40 \mathrm{kDa}$; $\mathrm{B})$ and the respective loading control $\beta$-tubulin $(\sim 50 \mathrm{kDa} ; \mathrm{B})$ are shown for the SHC and CSC mice following both time points.

the factors $\operatorname{CSC}\left(F_{1,27}=9.05 ; P=0.006\right)$ and duration $\left(F_{1,27}=28.90 ; P<0.001\right)$ as well as on the interaction between both the factors $\left(F_{1,27}=28.90 ; P<0.001\right)$, and adrenal mRNA expression of $C y p 11 b 1$ was dependent on the factor duration $\left(F_{1,27}=80.68 ; P<0.001\right)$ and on the interaction between the factors CSC and duration $\left(F_{1,27}=80.67 ; P<0.001\right)$. Post hoc analysis further revealed that mRNA expression of Cyp11a1 was significantly decreased in the CSC mice compared with the SHC mice following $10 \mathrm{~h}(P<0.001 ; d=2.63)$, but not $48 \mathrm{~h}$, of CSC. Consequently, mRNA expression of Cyp11a1 was significantly higher in the CSC mice at the 48-h time point compared with the $10-\mathrm{h}$ time point $(P<0.001 ; d=4.40)$. Cyp11b1 mRNA expression in the CSC mice compared with the SHC mice was significantly decreased following $10 \mathrm{~h}$ $(P<0.001 ; d=3.58)$ and significantly increased following $48 \mathrm{~h}(P<0.001 ; d=3.05)$ of CSC exposure. Consequently,
mRNA expression of Cyp11b1 was also significantly higher in the CSC mice at the 48-h time point compared with the 10 -h time point $(P<0.001 ; d=5.39$; Table 1$)$.

\section{Discussion}

The findings of the present study indicate that basal hypercorticism during the initial phase of CSC exposure is not prevented by the development of an attenuated ACTH responsiveness of the adrenal glands. They rather suggest that the normalization of initially increased basal morning plasma CORT concentrations following $48 \mathrm{~h}$ of CSC exposure is mediated by an attenuated pituitary ACTH release and the restoration of normal functional adrenal mass. Although the data of the present study further suggest an enhanced enzymatic inactivation of CORT and a normalization of steroidogenic enzyme expression to at least partly contribute to the normalization of basal plasma CORT levels following $48 \mathrm{~h}$ of CSC exposure, future studies need to address this in detail.

To investigate basal HPA axis activity during the initial phase of CSC exposure, mice were killed in the morning following either 10 or $48 \mathrm{~h}$ of psychosocial stressor exposure. In line with previous findings (Reber et al. 2007, 2011), basal morning plasma CORT concentrations were significantly increased in the CSC mice compared with the SHC mice following $10 \mathrm{~h}$ (eight- to ninefold), but not $48 \mathrm{~h}$, of CSC exposure. By contrast, basal morning plasma ACTH concentrations were increased following $10 \mathrm{~h}$ as well as $48 \mathrm{~h}$ of CSC, with the increase being less pronounced following the latter. Together, these findings at first glance support our initial hypothesis that the attenuated adrenal ACTH responsiveness observed following 19 days of CSC exposure (Uschold-Schmidt et al. 2012) already develops during the initial phase of psychosocial stressor exposure to prevent chronic basal hypercorticism.

However, although basal morning plasma CORT levels were increased following $10 \mathrm{~h}$, but not $48 \mathrm{~h}$, of CSC exposure, relative in vivo adrenal CORT content was found to be increased in the CSC mice compared with the SHC mice at both time points. Interestingly, this increase was again less pronounced following $48 \mathrm{~h}$ than following $10 \mathrm{~h}$ of CSC, well in line with the changes observed in plasma ACTH concentrations and, thus, clearly arguing against our initial hypothesis. The idea of fully ACTH-sensitive adrenal glands during this initial CSC phase is further supported by the fact that the statistical analysis even revealed a positive correlation of in vivo adrenal CORT content with plasma ACTH

Published by Bioscientifica Ltd. 
Table 1 Effects of 10 and $48 \mathrm{~h}$ of CSC exposure on adrenal mRNA expression of Star, Cyp11a1, and Cyp11b1. SHC and CSC mice were killed following either 10 or $48 \mathrm{~h}$ of CSC exposure. The left and right adrenal glands were removed and pruned of fat. Afterwards, total RNA was extracted from each left adrenal gland of the SHC and CSC mice and reverse-transcribed into CDNA for the determination of adrenal mRNA expression of Star, Cyp11a1, and Cyp11b1 via qPCR using TaqMan technology normalized to mRNA expression of the housekeeping gene Gapdh. SHC values were set to $100 \%$, and the percentage change in mRNA expression following 10 or $48 \mathrm{~h}$ of CSC exposure was calculated. Numbers in parentheses indicate group sizes. Data represent means+ S.E.M.

\begin{tabular}{|c|c|c|c|c|}
\hline & \multicolumn{2}{|c|}{$10 \mathrm{~h}$} & \multicolumn{2}{|c|}{$48 h$} \\
\hline & SHC (8) & $\operatorname{CSC}(8)$ & SHC (8) & $\operatorname{CSC}(7)$ \\
\hline Star & $100.00+3.76$ & $83.41+3.67$ & $100.00+7.66$ & $106.29+8.38$ \\
\hline Cyp11a1 & $100.00+5.91$ & $58.75+5.16^{*}$ & $100.00+4.65$ & $111.65+3.05^{\dagger}$ \\
\hline Сyp11b1 & $100.00+3.52$ & $69.89+2.29 *$ & $100.00+1.99$ & $137.78+6.49^{*, \dagger}$ \\
\hline
\end{tabular}

${ }^{\star} P<0.001$ vs respective SHC mice and ${ }^{\dagger} P<0.001$ vs respective 10 -h time point.

concentrations in the CSC mice in the present study. Furthermore, relative in vitro CORT secretion in response to ACTH (100 nM) was comparable between the SHC and CSC mice following both 10 and $48 \mathrm{~h}$ of CSC exposure, also suggesting an unaffected adrenal responsiveness to the main CORT secretagogue.

Given that plasma CORT concentrations were comparable between the SHC and CSC mice, despite a still increased relative in vivo adrenal CORT content following $48 \mathrm{~h}$ of CSC exposure, this suggests an enhanced enzymatic inactivation of CORT at that time point, contributing at least partly to the prevention of prolonged basal hypercorticism. Enzymatic degradation of CORT in its biologically inactive 11-keto form is mainly mediated by HSD11B2, most highly expressed in aldosterone target tissues such as the kidney (for review, see Seckl \& Walker (2001)). Importantly, although relative protein levels of HSD11B2 in the kidney were unaffected following both 10 and $48 \mathrm{~h}$ of CSC exposure, the activity of this enzyme might still be enhanced in the CSC mice compared with the SHC mice and needs to be addressed in future studies.

To investigate whether alterations in the expression levels of key steroidogenic enzymes are likely to contribute to the changes in basal morning plasma CORT concentrations during the initial phase of CSC exposure, we further analyzed the mRNA expression levels of Star, Cyp11a1, and Cyp11b1 following both 10 and $48 \mathrm{~h}$ of CSC exposure. In contrast to what one would expect if changes in steroidogenic enzyme expression indeed contribute to the changes in basal plasma CORT concentrations during the initial CSC phase, the expression levels of these enzymes were unaffected (Star) or significantly decreased (Cyp11a1 and Cyp11b1) following $10 \mathrm{~h}$ of CSC exposure and either unaffected (Star and Cyp11a1) or even increased (Cyp11b1) following $48 \mathrm{~h}$ of CSC exposure. However, it has been repeatedly shown for adrenal tissue that mRNA and protein expression levels of steroidogenic enzymes do not necessarily correspond to each other (Lehoux et al. 1992, 1998). Therefore, a divergent regulation of protein expression of these enzymes in the present study is not unlikely, probably contributing to the changes in basal morning plasma CORT concentrations during the initial phase of CSC exposure.

In one of our previous studies, we showed that relative adrenal mass is significantly increased during CSC at all time points assessed, beginning as early as $24 \mathrm{~h}$ after the start of chronic psychosocial stressor exposure (Reber et al. 2007). In the present study, we confirmed the increase in relative adrenal weight following $48 \mathrm{~h}$ of CSC exposure and extended these findings even to the 10-h CSC time point. However, in contrast to relative adrenal weight, absolute weight of both the left and right adrenal glands was increased only after $10 \mathrm{~h}$, but not $48 \mathrm{~h}$, of CSC exposure. Considering the CSC-induced reduction in body weight following both 10 and $48 \mathrm{~h}$ of CSC exposure, which is in line with previous findings (Slattery et al. 2012), this clearly indicates that the increase in relative left and right adrenal weights observed following $48 \mathrm{~h}$ of CSC is exclusively due to changes in body weight and not to changes in the adrenal weight itself. Interestingly, these findings seem to be in line with those of our abovementioned study assessing the time course of relative adrenal weight during CSC exposure. Although relative adrenal weight of the CSC mice was increased compared with the SHC mice at all the time points assessed, a closer look at this parameter during the initial CSC phase clearly

Published by Bioscientifica Ltd. 
indicates a pronounced drop in relative adrenal weight at the 48-h time point (Reber et al. 2007). Taken together, the changes in absolute adrenal weight during the initial phase of CSC seem to run in parallel with the changes in basal morning plasma CORT levels. Following $10 \mathrm{~h}$ of CSC exposure, both parameters are significantly increased, whereas following $48 \mathrm{~h}$ of CSC exposure, both parameters return to baseline values. Thus, it seems that reversing the early increase in adrenal mass in the CSC mice $(10 \mathrm{~h})$ contributes, at least partly, to prevent them from prolonged exposure to elevated plasma CORT levels. This is supported by previous studies showing a positive correlation between plasma CORT concentrations and adrenal weight under stress conditions in rats (Schwartz et al. 1997, Baranyi et al. 2005). However, future studies are needed to clarify whether these early changes in absolute adrenal weight are mediated by hyper/hypotrophy or by hyperplasia/apoptosis of adrenal cells.

In summary, the data of the present study indicate that elevated basal morning plasma CORT levels following $10 \mathrm{~h}$ of CSC exposure seem to be due to a concurrent increase in the release of pituitary ACTH and functional adrenal tissue in both the left and right adrenal glands and not to changes in adrenal ACTH responsiveness. Whether and to what extent an altered mRNA turnover of key steroidogenic enzymes is involved in the CSC-induced initial changes in plasma CORT levels need to be addressed in future studies. Furthermore, in contrast to the situation faced following 19 days of CSC exposure, at which hypercorticism seems to be prevented by a reduction in adrenal ACTH responsiveness, basal hypercorticism during the initial phase of CSC seems to be prevented by an attenuated release of pituitary ACTH and, most likely to a lesser degree, by restoration of normal functional adrenal mass. Whether and to what extent an enhanced enzymatic inactivation of CORT, which is clearly suggested by the findings of the present study, plays a crucial role also has to be addressed in future studies. Thus, together with previous findings (Uschold-Schmidt et al. 2012), our data suggest different mechanisms to be involved in the restoration of normal basal plasma CORT concentrations and, consequently, in the prevention of basal hypercorticism during either the initial or chronic phase of homotypic psychosocial stressor exposure.

\section{Declaration of interest}

The authors declare that there is no conflict of interest that could be perceived as prejudicing the impartiality of the research reported.

\section{Funding}

This study was supported by the German Research Foundation (research grant RE 2911/5-1). The funders had no role in study design, data collection, and analysis, decision to publish, or preparation of the manuscript.

\section{Author contribution statement}

N U-S was responsible for the conception and design of experiments, collection, analysis and interpretation of data, and manuscript writing. $\mathrm{D} P$ and $\mathrm{A} M \mathrm{M}$ were responsible for the collection and analysis of data. $S O R$ was responsible for the conception and design of experiments, revision of the manuscript, and supervision of the project.

\section{Acknowledgements}

The authors are grateful to N Grunwald and C Stangl for their excellent experimental assistance.

\section{References}

Baranyi J, Bakos N \& Haller J 2005 Social instability in female rats: the relationship between stress-related and anxiety-like consequences. Physiology \& Behavior 84 511-518. (doi:10.1016/j.physbeh.2005.01.005)

Bartolomucci A 2007 Social stress, immune functions and disease in rodents. Frontiers in Neuroendocrinology 28 28-49. (doi:10.1016/ j.yfrne.2007.02.001)

Biason-Lauber A 1998 Molecular medicine of steroid hormone biosynthesis. Molecular Aspects of Medicine 19 155-220. (doi:10.1016/ S0098-2997(98)00004-1)

Charmandari E, Tsigos C \& Chrousos G 2005 Endocrinology of the stress response. Annual Review of Physiology 67 259-284. (doi:10.1146/ annurev.physiol.67.040403.120816)

Chrousos GP 1998 Stressors, stress, and neuroendocrine integration of the adaptive response. The 1997 Hans Selye Memorial Lecture. Annals of the New York Academy of Sciences $\mathbf{8 5 1}$ 311-335. (doi:10.1111/j.1749-6632. 1998.tb09006.x)

Füchsl AM, Uschold-Schmidt N \& Reber SO 2013 Chronic psychosocial stress in male mice causes an up-regulation of scavenger receptor class B type 1 protein in the adrenal glands. Stress. In press. (doi:10.3109/ 10253890.10252013.10793303)

Kudielka BM, von Kanel R, Preckel D, Zgraggen L, Mischler K \& Fischer JE 2006 Exhaustion is associated with reduced habituation of free cortisol responses to repeated acute psychosocial stress. Biological Psychiatry 72 147-153. (doi:10.1016/j.biopsycho.2005.09.001)

Lehoux JG, Mason JI \& Ducharme L 1992 In vivo effects of adrenocorticotropin on hamster adrenal steroidogenic enzymes. Endocrinology 131 1874-1882. (doi:10.1210/en.131.4.1874)

Lehoux JG, Fleury A \& Ducharme L 1998 The acute and chronic effects of adrenocorticotropin on the levels of messenger ribonucleic acid and protein of steroidogenic enzymes in rat adrenal in vivo. Endocrinology 139 3913-3922. (doi:10.1210/en.139.9.3913)

McEwen BS 2000 Allostasis and allostatic load: implications for neuropsychopharmacology. Neuropsychopharmacology 22 108-124. (doi:10.1016/S0893-133X(99)00129-3)

Miller WL 1988 Molecular biology of steroid hormone synthesis. Endocrine Reviews 9 295-318. (doi:10.1210/edrv-9-3-295)

Reber SO \& Neumann ID 2008 Defensive behavioral strategies and enhanced state anxiety during chronic subordinate colony housing are accompanied by reduced hypothalamic vasopressin, but not oxytocin, expression. Annals of the New York Academy of Sciences 1148 184-195. (doi:10.1196/annals.1410.003)

Reber SO, Birkeneder L, Veenema AH, Obermeier F, Falk W, Straub RH \& Neumann ID 2007 Adrenal insufficiency and colonic inflammation

Published by Bioscientifica Ltd. 
after a novel chronic psycho-social stress paradigm in mice: implications and mechanisms. Endocrinology 148 670-682. (doi:10.1210/ en.2006-0983)

Reber SO, Peters S, Slattery DA, Hofmann C, Scholmerich J, Neumann ID \& Obermeier F 2011 Mucosal immunosuppression and epithelial barrier defects are key events in murine psychosocial stress-induced colitis. Brain, Behavior, and Immunity 25 1153-1161. (doi:10.1016/j.bbi.2011. 03.004)

Sapolsky RM 1996 Why stress is bad for your brain. Science 273 749-750. (doi:10.1126/science.273.5276.749)

Sasse SK, Greenwood BN, Masini CV, Nyhuis TJ, Fleshner M, Day HE \& Campeau S 2008 Chronic voluntary wheel running facilitates corticosterone response habituation to repeated audiogenic stress exposure in male rats. Stress 11 425-437. (doi:10.1080/10253890801887453)

Schwartz MW, Strack AM \& Dallman MF 1997 Evidence that elevated plasma corticosterone levels are the cause of reduced hypothalamic corticotrophin-releasing hormone gene expression in diabetes. Regulatory Peptides 72 105-112. (doi:10.1016/S0167-0115(97)01043-4)
Seckl JR \& Walker BR 2001 Minireview: 11ß-hydroxysteroid dehydrogenase type 1 - a tissue-specific amplifier of glucocorticoid action. Endocrinology 142 1371-1376. (doi:10.1210/en.142.4.1371)

Singewald GM, Nguyen NK, Neumann ID, Singewald N \& Reber SO 2009 Effect of chronic psychosocial stress-induced by subordinate colony (CSC) housing on brain neuronal activity patterns in mice. Stress $\mathbf{1 2}$ 58-69. (doi:10.1080/10253890802042082)

Slattery DA, Uschold N, Magoni M, Bar J, Popoli M, Neumann ID \& Reber SO 2012 Behavioural consequences of two chronic psychosocial stress paradigms: anxiety without depression. Psychoneuroendocrinology 37 702-714. (doi:10.1016/j.psyneuen.2011.09.002)

Uschold-Schmidt N, Nyuyki KD, Fuechsl AM, Neumann ID \& Reber SO 2012 Chronic psychosocial stress results in sensitization of the HPA axis to acute heterotypic stressors despite a reduction of adrenal in vitro ACTH responsiveness. Psychoneuroendocrinology 37 1676-1687. (doi:10.1016/j.psyneuen.2012.02.015)

Vanitallie TB 2002 Stress: a risk factor for serious illness. Metabolism: Clinical and Experimental $\mathbf{5 1}$ 40-45. (doi:10.1053/meta.2002.33191)

Received in final form 23 May 2013

Accepted 28 May 2013

Accepted Preprint published online 29 May 2013 http://joe.endocrinology-journals.org DOI: 10.1530/JOE-13-0027
(C) 2013 Society for Endocrinology Printed in Great Britain
Published by Bioscientifica Ltd. 